\title{
A fatal case of Brazilian spotted fever in a non-endemic area in Brazil: the importance of having health professionals who understand the disease and its areas of transmission
}

\author{
Stefan Vilges de Oliveira [1], [2], [3], Eduardo Pacheco de Caldas[1], Silvia Colombo ${ }^{[4],}$ \\ Gilberto Salles Gazeta ${ }^{[3]}$, Marcelo Bahia Labruna ${ }^{[5]}$, Fabiana Cristina Pereira dos Santos ${ }^{[4]}$ \\ and Rodrigo Nogueira Angerami[6]
}

[1]. Secretaria de Vigilância em Saúde, Ministério da Saúde, Brasília, Distrito Federal, Brasil. [2]. Programa de Pós-Graduação em Medicina Tropical, Universidade de Brasília, Brasília, Distrito Federal, Brasil. [3]. Laboratório de Referência Nacional em Vetores das Riquetsioses, Fundação Oswaldo Cruz, Rio de Janeiro, Rio de Janeiro, Brasil. [4]. Laboratório de Riquétsias, Instituto Adolfo Lutz, São Paulo, São Paulo, Brasil. [5]. Departamento de Medicina Veterinária Preventiva e Saúde Animal, Universidade de São Paulo, São Paulo, Brasil. [6]. Hospital das Clínicas, Universidade Estadual de Campinas, Campinas, São Paulo, Brasil.

\begin{abstract}
Brazilian spotted fever (BSF) is caused by the bacterium Rickettsia rickettsii. Because of its high case-fatality rate and apparent increase in areas of transmission, it is considered to be the rickettsial illness of primary public health interest. Cases of this disease have historically occurred in Southeastern Brazil. This article reports the first fatal case of BSF in Southern Brazil. This case high lights the importance of BSF to be considered as a differential diagnosis for acute hemorrhagic fever in areas where cases of BSF may not be expected.
\end{abstract}

Keywords: Rickettsial illness. Rickettsia rickettsii. Tick-borne diseases.

\section{INTRODUCTION}

Brazilian spotted fever (BSF) is a rickettsial illness caused by the bacterium Rickettsia rickettsii ${ }^{(1)}$. It is transmitted to humans by ticks, most commonly by the species Amblyomma sculptum (formerly Amblyomma cajennense), which is considered to be the main vector of the disease in $\mathrm{Brazil}^{(2)}$.

Early diagnosis of BSF is often difficult, particularly during the first few days of the illness. The lack of specificity in its clinical signs results in low suspicion. The classical clinical marker, exanthema, is not always present, making appropriate medical conduct difficult ${ }^{(3)}$. This difficulty leads to possible consequences, such as the use of inappropriate therapies and, as a result, a greater risk of severe cases and death ${ }^{(4)}$. The main challenge is making a differential diagnosis relative to other more common and more widespread diseases, such as dengue fever and leptospirosis ${ }^{(5)}$.

Fatal cases of Rickettsia rickettsii infection have thus far been reported inonly four Brazilian states, all of which are

Corresponding author: Msc. Stefan Vilges de Oliveira.

e-mail: stefan.oliveira@saude.gov.br

Received 10 March 2016

Accepted 5 May 2016 located in the Southeastern region of the country: São Paulo ${ }^{(6)}$, Minas Gerais ${ }^{(7)}$, Rio de Janeiro ${ }^{(8)}$, and Espírito Santo ${ }^{(9)}$. The case-fatality rate has been found to range from $30 \%$ to $50 \%{ }^{(5)}$. Although infections caused by unknown spotted fever group agents of the genus Rickettsia have been reported in the Southern states of Brazil ${ }^{(1)}$, there have been no confirmed cases or fatalities due to $R$. rickettsii. This report presents the first record of a human death caused by $R$. rickettsii in the Brazilian State of Paraná, located in the southern region of the country.

\section{CASE REPORT}

The patient was a 12-year-old girl from the City of São Carlos de Ivaí, located in the Northern part of Paraná State in Southern Brazil. On January 3, 2015, the patient presented with symptoms of hyporexia and weakness, followed by frontal headaches and a dry cough. She was medicated by family members with paracetamol, dipyrone, and diclofenac. On the seventh day, the patient presented with fever and abdominal pain. At this point, she sought medical attention. She was given paracetamol and discharged. On the ninth day of symptoms, the patient's condition worsened and she was hospitalized with suspected dengue fever based on her symptoms of fever, myalgia, headache, vomiting, exanthema, and dehydration. Tests to detect the NS1 antigen for dengue were negative, and blood tests revealed the presence of leukopenia and thrombocytopenia. During hospitalization, physicians 
administered only symptomatic medication and parenteral hydration with crystalloids. On the $11^{\text {th }}$ day, the patient presented with exanthema and a reduced level of consciousness, as well as psychomotor restlessness, anuria, worsened thrombocytopenia, and leukocytosis. Antibiotic therapy with ceftriaxone was initiated. The patient was transferred to the intensive care unit (ICU), where she had seizures. At this point, meningitis was suspected. The patient's condition worsened, and hemodynamic and ventilatory support were initiated. These measures were provided by an ICU in a neighboring city, where the patient died on the $13^{\text {th }}$ day of the illness.

Laboratory investigations included immunologic and molecular analyses of a serum sample collected on January 14 (the $11^{\text {th }}$ day of the patient's illness) for a diagnosis of spotted fever group rickettsiosis. An immunofluorescence antibody assay using $R$. ricketsii as the antigen yielded an immunoglobulin $\mathrm{G}(\mathrm{IgG})$ concentration of $<64 \mathrm{mg} / \mathrm{dL}$ and an immunoglobulin $\mathrm{M}$ (IgM) concentration of $128 \mathrm{mg} / \mathrm{dL}$. For a molecular analysis, a serum sample was submitted for deoxyribonucleic acid (DNA) extraction using the PureLink ${ }^{\circledR}$ Viral ribonucleic acid/ deoxyribonucleic acid (RNA/DNA) Mini Kit (Invitrogen, Carlsbad, CA, USA) and tested with two real-time polymerase chain reaction (PCR) assays: one targeting the rickettsial gltA gene of any member of the Rickettsia family ${ }^{(10)}$, and another specific to $R$. rickettsii, targeting the hypothetical protein A1G_04230(11). Results of the patient's serum DNA were positive for both assays.

In an epidemiological investigation performed post-mortem, it was found that the patient had a history of travel to a farm with a lake inhabited by capybaras (Hydrochoerus hydrochaeris) within Ribeirão Claro municipality, Paraná State. During her last trip, she remained on the farm for 16 days. Her symptoms began the day after she returned. Because capybaras are considered to be the most important source of $R$. rickettsii infection to A. sculptum ticks in southeastern Brazil ${ }^{(1)(3)}$, it is possible that BSF would have been suspected during the first days of illness had the information of the contact with capybaras been shared with the physicians. On the other hand, the physicians' unfamiliarity with spotted fever rickettsiosis could also have contributed to the lack of BSF suspicious. Finally, the patient's city of residence (São Carlos do Ivaí) was experiencing a dengue fever epidemic at the time, which could have hampered the suspicious of other vector-borne diseases.

\section{DISCUSSION}

Brazilian spotted fever has been considered one of the main challenges to public health in Brazil, particularly because of its high case-fatality rates. Factors that may be associated with the low rate of suspicion of BSF include health care professionals' lack of knowledge on the clinical features of the disease, the eco-epidemic aspects associated with the risk of infection, and the risk factors for exposure to the vector and to the transmission areas of the disease ${ }^{(3)}$.

The current case reflects the potential for the development of serious forms of the disease with systemic bodily dysfunction, such as respiratory and renal failure, hemorrhagic manifestations, neurological changes, and shock ${ }^{(5)}$. This report also demonstrates that BSF frequently goes unrecognized as a diagnostic hypothesis and is frequently confused with more prevalent illnesses, such as leptospirosis, dengue fever, and meningococcal disease ${ }^{(3)}$. In fact, the latter two were considered by physicians in the present case.

Dengue fever is the vector-borne disease with the most substantial impact in Brazil. Recent arbovirus events (which also cause febrile symptoms) represent a significant challenge when it comes to appropriate medical interventions in cases of BSF. The case in question is particularly noteworthy because of two factors that contributed to the outcome: 1) epidemiological history was not considered as part of the patient's clinical history during her treatment process, and so it was not determined that she had been in an area that was eco-epidemiologically associated with the risk of infection because it was a rural area inhabited by capybaras; and 2) no one considered the possibility that the infection developed in alocation different from the patient's city of residence that was endemic for the disease and where the patient traveled for leisure activities. If these possibilities had been considered during medical treatment, they would likely have contributed to a greater suspicion of BSF, making the use of appropriate antibiotic treatment more likely and, as a result, reducing the risk of death by BSF.

Current treatment protocols for BSF include doxycycline, an antibiotic indicated for the treatment of $R$. rickettsii infection and other tick-borne diseases. Indeed, doxycycline is the first choice for treating clinical rickettsioses, regardless of a patient's age $^{(12)}$. However, without more knowledge of the disease and the risk factors for infection, and considering the importance of introducing early adequate antibiotic treatment, it is unlikely that the treatment protocol will reduce case-fatality $\operatorname{rates}^{(3)(4)(5)}$.

In conclusion, this report describes the first fatal case of BSF in a new endemic area of southern Brazil. The findings reflect the need for both early identification of new transmission areas and training for health care professionals to diagnose suspicious cases. This report therefore provides indispensable information to the search for methods to decrease deaths associated with BSF in Brazil.

\section{Acknowledgements}

We would like to thank the team from the Zoonosis Surveillance Technical Unit, the technical group for rodent-related diseases from the Brazilian Ministry of Health, and the team for epidemiological and environmental surveillance of Paraná.

\section{Conflicts of Interest}

The authors declare that they have no conflicts of interest.

\section{REFERENCES}

1. Labruna MB, Mattar SV, Nava S, Bermudez S, Venzal JM, Dolz $\mathrm{G}$, et al. Rickettsioses in Latin America, Caribbean, Spain and Portugal. Rev MVZ Cordoba 2011; 16:2435-2457.

2. Nava S, Beati L, Labruna MB, Cáceres AG, Mangold AJ, Guglielmone AA. Reassessment of the taxonomic status of 
Amblyomma cajennense with the description of three new species, Amblyomma tonelliae n. sp., Amblyomma interandinum n. sp. and Amblyomma patinoi n. sp., and reinstatement of Amblyomma mixtum, and Amblyomma sculptum (Ixodida, Ixodidae). Ticks Tick Borne Dis 2014; 5:252-276.

3. Angerami RN, Câmara M, Pacola MR, Rezende RCM, Duarte RMR, Nascimento EMM, et al. Features of Brazilian spotted fever in two different endemic areas in Brazil. Ticks Tick Borne Dis 2012; 3:346-348.

4. Paddock CD, Guerra MA, Childs JE. Rickettsia rickettsii (Rocky Mountain spotted fever). In: Long SS, Larry K, Pickering LK, Prober CG, editors. Principles and Practice of Pediatric Infectious Diseases, $4 \mathrm{t}^{\mathrm{h}}$ edition. Elsevier, 2008. p. 926-929.

5. Walker DH, Raoult D. Rickettsia ricketsii and other spotted fever group rickettsiae (Rocky Mountain spotted fever and other spotted fever). In: Mendel GL, Bennett JE, Dolin R, editors. Mandell, Douglas, and Bennett's Principles and Practices of Infectious Diseases. $6^{\text {th }}$ edition. Philadelphia, PA: Churchill Livingstone; 2005. p. 2287-2295.

6. Labruna MB, Santos FC, Ogrzewalska M, Nascimento EM, Colombo S, Marcili A, et al. Genetic identification of rickettsial isolates from fatal cases of Brazilian spotted fever and comparison with Rickettsia rickettsii isolates from the American continents. J ClinMicrobiol 2014; 52:3788-3791.

7. Galvão MA, Dumler JS, Mafra CL, Calic SB, Chamone CB, Cesarino FG, et al., Fatal spotted fever rickettsiosis, Minas Gerais, Brazil. Emerg Infect Dis 2003; 9:1402-1405.
8. Lemos ERS, Rozental T, Villela CL. Febre maculosa brasileira: descrição de um caso fatal no estado do Rio de Janeiro. Rev Soc Bras Med Trop 2002; 35:523-525.

9. Sexton DJ, Muniz M, Corey GR, Breitschwerdt EB, Hegarty BC, Dumler S, et al. Brazilian spotted fever in Espírito Santo, Brazil: description of a focus of infection in a new endemic region. Am J Trop Med Hyg 1993; 49:222-226.

10. Labruna MB, Whitworth T, Horta MC, Bouyer DH, McBride JW, Pinter A, et al. Rickettsia species infecting Amblyomma cooperi ticks from an area in the state of São Paulo, Brazil, where Brazilian spotted fever is endemic. J Clin Microbiol 2004; 42:90-98.

11. Kato CY, Chung IH, Robinson LK, Austin AL, Dasch GA, Massung RF. Assessment of real-time PCR assay for detection of Rickettsia spp. and Rickettsia rickettsii in banked clinical samples. J Clin Microbiol 2013; 51:314-317.

12. Ministério da Saúde. Departamento de Gestão e Incorporação de Tecnologias em Saúde da Secretaria de Ciência, Tecnologia e Insumos Estratégicos. Portaria ${ }^{\circ} 16$, de 15 de maio de 2014. Torna pública a decisão de incorporar a doxicilina injetável e o cloranfenicol suspensão para terapêutica da febre maculosa brasileira e outras riquetsioses demandante no Sistema Único de Saúde - SUS. Available in: http://conitec.gov.br/images/ Incorporados/Doxiciclina-e-Clorafenicol-FINAL.pdf. 